\title{
Non-linear buckling analysis of composite columns made from high and normal strength concrete under fire
}

\author{
Abdelkadir Fellouh $^{1}$ (D) $\cdot$ Abdelkader Bougara $^{1} \cdot$ Paulo A. G. Piloto ${ }^{2} \cdot$ Nourredine Benlakehal $^{1}$
}

Received: 25 July 2018 / Accepted: 2 August 2019

(c) Springer Nature Switzerland AG 2019

\begin{abstract}
Composite structures made from the combination of steel profile and concrete have significant loadbearing capacity which depends on the behaviour of the two material components and their interaction, particularly in fire conditions. It is not possible to assess the fire resistance of composite members only by considering the temperature of the steel, because the presence of the concrete may contribute greatly to increase the resistance, strength and thermal inertia of the member, which improves consequently the fire behaviour of the element. The aim of this work is to develop an efficient non-linear 3D finite element model to investigate the behaviour of pin-ended axially loaded composite column made from high strength concrete (HSC) and normal strength concrete (NSC) at different fire rating classes. Two types of column section were selected, notably HEB 160 profile totally encased with concrete and HEB220 partially encased with concrete. The fire behaviour of the columns was tested according to ISO834 standard fire. The results show that the use of HSC in composite columns reduces the level of fire protection with the regard to NSC. NSC in composite structures accommodates higher deflections than HSC, which is safer in case of fire accident. The mechanical resistance in composite columns at room temperature is reduced more than twice after $30 \mathrm{~min}$ of fire exposure.
\end{abstract}

Keywords Composite column $\cdot$ Fire $\cdot$ Concrete $\cdot$ Finite elements $\cdot$ Non-linear $\cdot$ Buckling

\section{Introduction}

Nowadays for building structures, the performance under fire conditions is much requested for safety and stability conditions. The construction industry gives significant importance to the use of high-strength concrete (HSC) over normalstrength concrete (NSC) at room temperature because of its best structural performance. Many studies have shown that HSC behaves differently with NSC at high temperatures (Moliner et al. 2013). The microstructure of the type of concrete may play a great role in modifying the thermal properties of concrete (Luccioni et al. 2003). Moreover, it is reported that HSC performs worse than NSC in fire because of its constituent materials (Gernay 2016). The relative loss of compressive strength with temperature and the higher

Abdelkadir Fellouh

a.fellouh@univ-chlef.dz

1 Laboratory of Structures, Geotechnic and Risks, Hassiba Benbouali University of Chlef (UHBC), Chlef, Algeria

2 Department of Applied Mechanics, Polytechnic Institute of Bragança (IPB), Bragança, Portugal probability occurrence of explosive spalling are two important factors in HSC that reduces the fire performance of this material (Kodur 2014).

Composite columns are usually made of hot rolled steel profiles, reinforced with concrete. Previous studies reported that the composite section in partially encased column (PEC) is responsible for increasing the torsional and bending stiffness when compared to the same section of the steel bare profile (Piquer and Hernández-Figueirido 2016). The authors show that PEC sections resist around $120 \mathrm{~min}$ before collapsing in fire conditions. Other investigations have found that totally encased steel sections (TEC) present a high loadbearing capacity and fire resistance. It was found that concrete cover have a big influence on the critical time of the columns, increasing the concrete cover around the steel profile and rebars increases the critical times and fire resistance (Rodrigues et al. 2015).

The use of HSC in multi-story buildings has become increasingly popular because of its high loadbearing resistance at room temperature. HSC concrete presents better strength and durability than NSC concrete (Afroughsabet and Ozbakkaloglu 2015) at room temperature. Another 
advantage for the selection of HSC over normal strength concrete (NSC) is that it allows for reducing the dimensions of the columns cross sections. However, this reduction has consequences on the structural performance in case of fire, as smaller cross sections lead to faster temperature increase in the core section. Reducing the cross section dimensions will affect second-order moment of area which is more considered in columns design as demonstrated by Bamonte (2008). Peter Schaumann et al. (2009) studied the non-linear fire behaviour of hollow structural section steel columns filled with HSC. They concluded that the micro cracking in HSC leads to faster loss of strength at high temperature.

The main objective of this study is to develop an efficient non-linear 3D finite element model to investigate the behaviour of pin-ended axially loaded composite columns made from HSC and NSC concrete at elevated temperatures. The model was developed using the software ANSYS (2016). The use of the finite element method to investigate the behaviour of HSC is due to the limitation of the simplified method (Eurocode 4) to normal strength concrete (NSC). This numerical analysis enables to assess the effect of the materials on the thermal and mechanical behaviour of composite columns under fire.

\section{Composite columns parametric study}

Two types of concrete (HSC-NSC) are considered for the composite columns to compare the thermal behaviour and the non-linear buckling resistance of composite columns. Two types of column were selected to investigate the effect of fire, notably HEB 160 profile totally encased with concrete (TEC) and HEB 220 profile partially encased with concrete (PEC) see Fig. 1.

This columns were tested under ISO834 fire (International Organization for Standardization 1999). The boundary conditions are pinned in both ends with column height of $3 \mathrm{~m}$. Properties for steel were assumed from S275 grade and B500 grade for profile and rebars, respectively, while grade C20/25 (NSC) and grade C80/95 (HSC) were assumed for concrete. Tables 1 and 2 present the geometrics properties of PEC and TEC.

Fig. 1 Cross section example

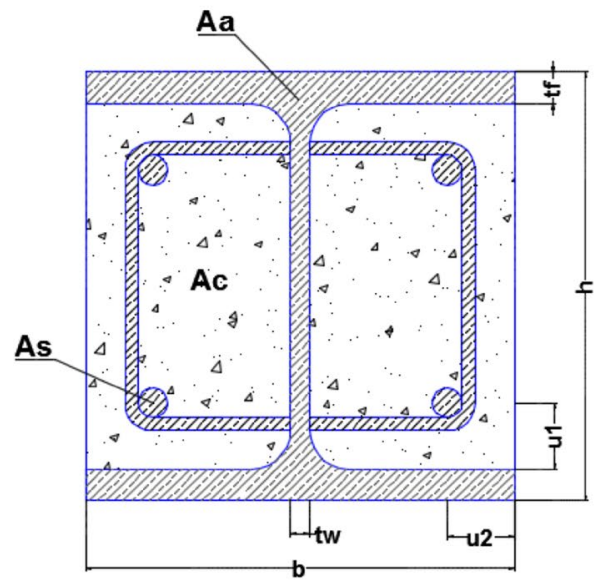

(a) Cross section model (PEC).

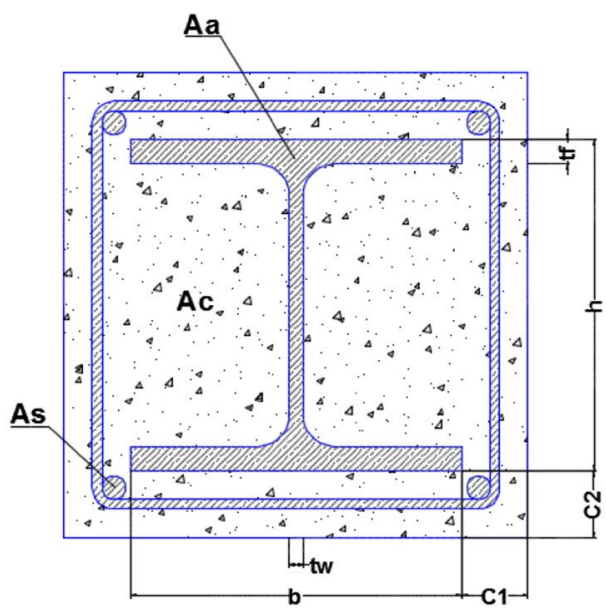

(b) Cross section model (TEC).

Table 1 Section properties for partially encased columns

\begin{tabular}{lllllllll}
\hline Profile & $b(\mathrm{~mm})$ & $h(\mathrm{~mm})$ & $t_{w}(\mathrm{~mm})$ & $t_{f}(\mathrm{~mm})$ & No. of bars & $u_{1}(\mathrm{~mm})$ & $u_{2}(\mathrm{~mm})$ & $\phi_{s}(\mathrm{~mm})$ \\
\hline HEB220 & 220 & 220 & 9.5 & 16 & 4 & 50 & 50 & 25 \\
\hline
\end{tabular}

Table 2 Section properties for totally encased columns

\begin{tabular}{|c|c|c|c|c|c|c|c|c|c|c|}
\hline Profile & $b(\mathrm{~mm})$ & $h(\mathrm{~mm})$ & $t_{w}(\mathrm{~mm})$ & $t_{f}(\mathrm{~mm})$ & $c_{1}(\mathrm{~mm})$ & $c_{2}(\mathrm{~mm})$ & No. of bars & $\phi_{s}(\mathrm{~mm})$ & $u_{1}(\mathrm{~mm})$ & $u_{2}(\mathrm{~mm})$ \\
\hline HEB160 & 160 & 160 & 8 & 13 & 50 & 50 & 4 & 12 & 30 & 30 \\
\hline
\end{tabular}




\section{Materials properties}

\section{Thermal properties of concrete}

The physical properties of concrete are significantly influenced by the aggregate type, moisture content, and composition of concrete mix. During the recent years, Kodur and Sultan (2003) have shown that the effect of fire on HSC can be estimated by relationships involving thermal concrete properties at elevated temperatures. These relationships are used in finite elements models for HSC in the present study. However for NSC, thermal properties can be found in Eurocode EN 1992-1-2 (CEN 2004) as plotted in Fig. 2, and those of the steel from EN 1993-1-2 (CEN 2005).

The thermal conductivity depends generally on the material components. For NSC and HSC made with siliceous aggregates, the temperature-dependent thermal conductivity decreases with the increase of temperature for both types of concrete, as illustrated in Fig. 2a. It is thought that this is due to the concrete mix properties (Kodur 2014). Moreover, because of the low water cement ratio $(W / C)$ of $\mathrm{HSC}$, its thermal conductivity is higher than

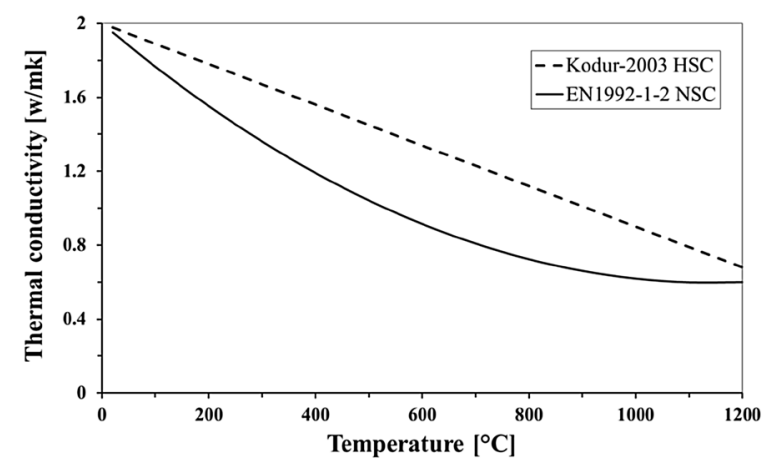

(a) Thermal conductivity of concrete.

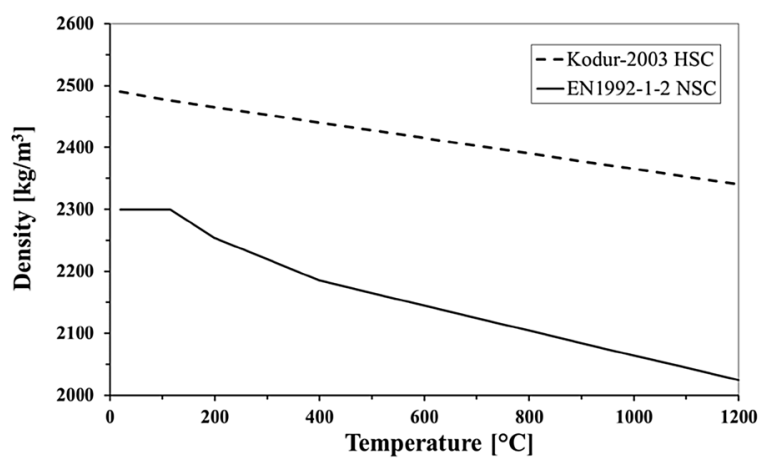

(c) Density of concrete. that of NSC. Figure $2 b$ illustrates the specific heat for both types of concrete. The specific heat of NSC displays a high peak at around $100{ }^{\circ} \mathrm{C}$; however, the HSC presents a relative small peak at around $500{ }^{\circ} \mathrm{C}$. At elevated temperatures (more than $500{ }^{\circ} \mathrm{C}$ ), the specific heat values of both concrete behave similar and no effect is noticed from the concrete composition (Kodur and Khaliq 2011). The specific density of both types of concrete is temperature dependent and is depicted in Fig. 2c. NSC shows higher mass loss with regard to HSC, probably justified by the amount of water content.

\section{Mechanical properties of concrete}

The reduction of compressive strength with temperature is defined by the coefficient $k_{c, t(\theta)}$, according to the values given in EN 1992-1-2 (CEN 2004) for NSC and HSC. Only class 2 of HSC is represented in this work as given in EN19921-2 (CEN 2004). The relative reduction in the compressive strength is more pronounced for HSC than NSC, as shown in Fig. 3. This effect is particularly visible for the lower temperature range $\left(50-400{ }^{\circ} \mathrm{C}\right)$. However, over $400{ }^{\circ} \mathrm{C}$ both types of concrete present the same behaviour. It seems that the coefficient $k_{c, t(\theta)}$ is independent of concrete properties

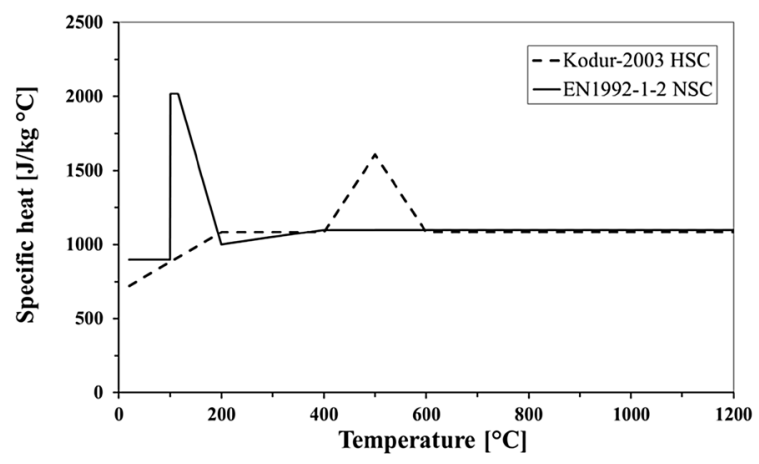

(b) Specific heat of concrete.

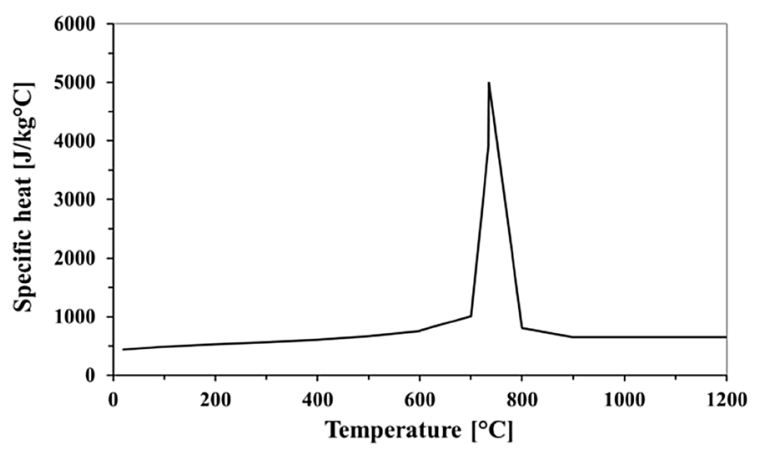

(d) Specific heat of steel.

Fig. 2 Thermal properties of concrete and steel 


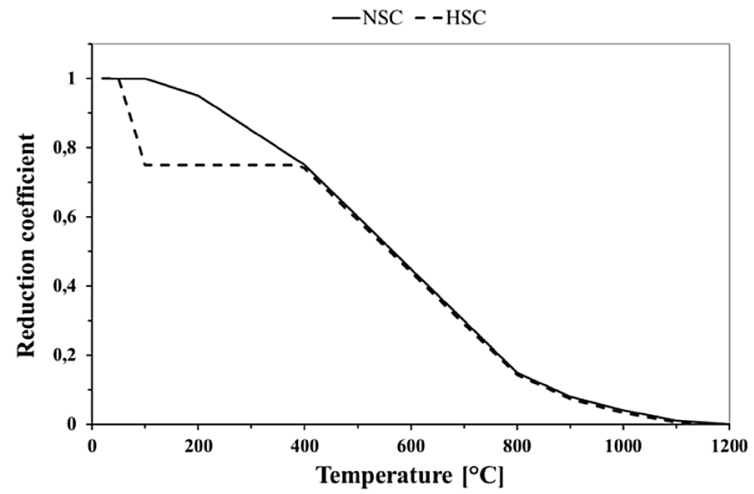

Fig. 3 Reduction of concrete compressive strength at elevated temperature (CEN 2004)

beyond this temperature limit. The mechanical properties of steel are given in accordance to EN 1993-1-2 (CEN 2005).

The expected nonlinear variation of the stress-strain for both concrete are plotted in Fig. 4. According to EN 19921-2 for NSC (CEN 2004) and kodur for HSC (Kodur et al. 2004), HSC has a higher initial slope than when compared to NSC. Also the Fig. 4 shows that NSC presents relatively higher ductility than HSC at low and high temperature, therefor the stress-strain curve at elevated temperatures has crucial influence on the fire response of structural systems.

From the previous curves, elastic modulus values are deduced using the elasticity formula and considering the secant elastic modulus corresponding to $40 \%$ of yield stress (see Fig. 5). The obtained values are used later in the elastic buckling analysis. Figure 5 shows the variation of elastic modulus with temperature. The elastic modulus for both concrete decreases with the increase of temperature, with higher rate for HSC when compared with NSC. This may be attributed to aggregate-cement ratio (Kodur and Mcgrath 2003).

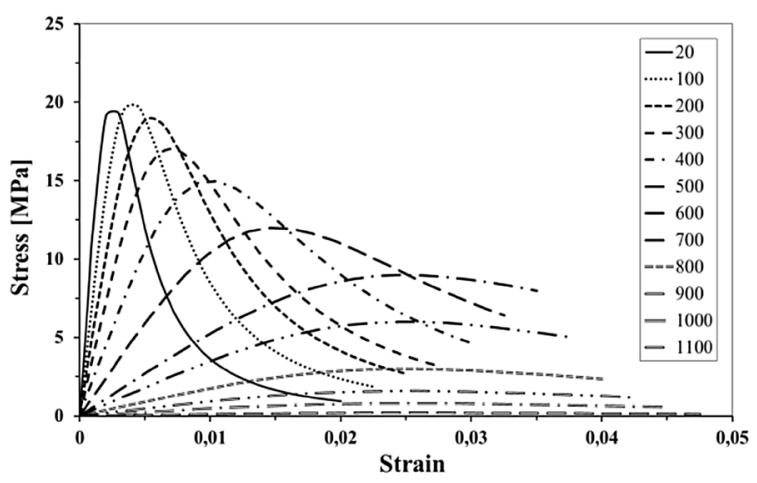

(a) NSC

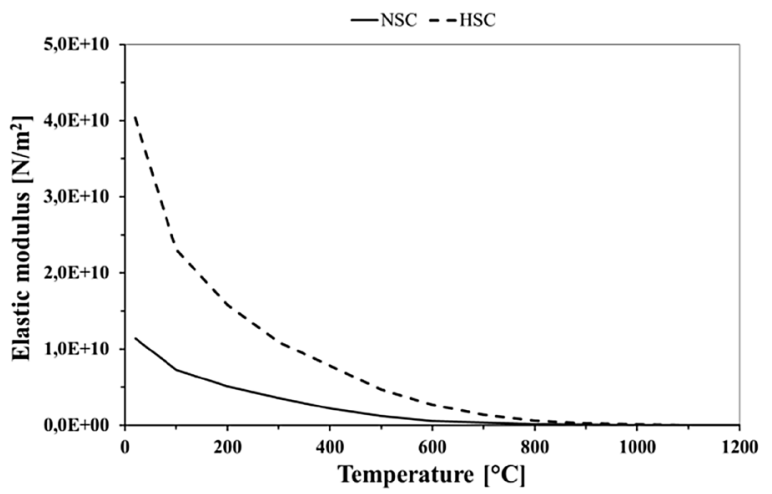

Fig. 5 Elastic modulus of concrete

\section{Advanced calculation method}

A numerical finite element model was used for predicting the behaviour of composite columns when exposed to fire. The numerical procedure used in this method is that which was previously applied to fire resistance calculations of composite section made with normal strength concrete (Fellouh et al. 2016). The composite columns investigated in this study are shown in Fig. 6.

The finite element approach consists of three sequential analysis steps, notably uncoupled thermal and mechanical analysis, in which the thermal results are used in the buckling analysis as thermal load for each different fire rating class R30-60-90.

The first step considers the nonlinear transient thermal analysis to calculate the temperature field, where only the four sides of the composite column are exposed to standard fire source ISO 834 (International Organization for Standardization 1999). The simulation method uses two different types of finite elements, notably SOLID70 and LINK33 (Albero et al. 2016). SOLID70 is used to model steel profile

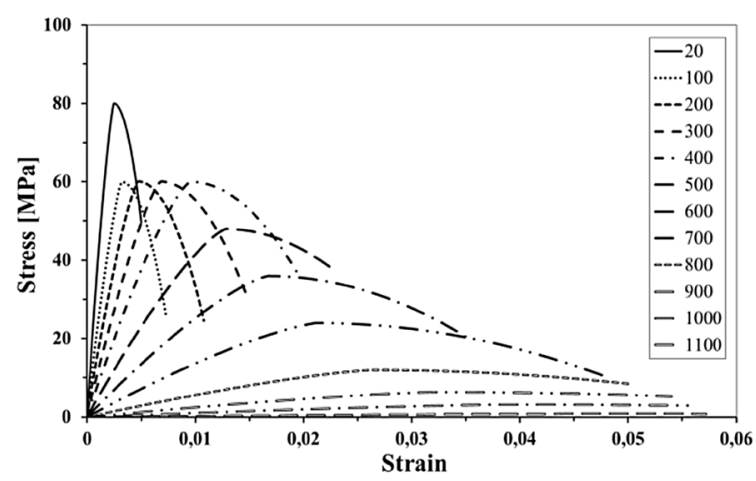

(b) HSC

Fig. 4 Stress-strain curve of concrete under compression 


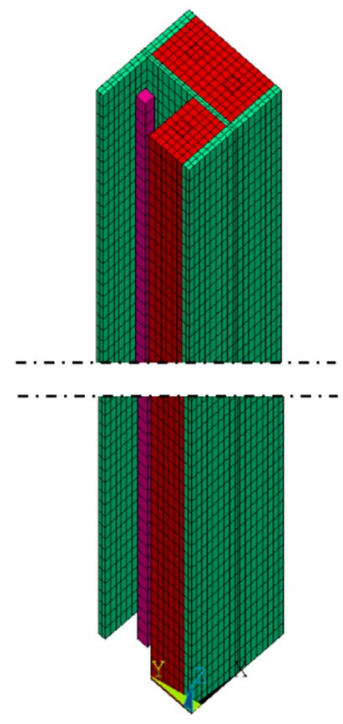

(a) PEC

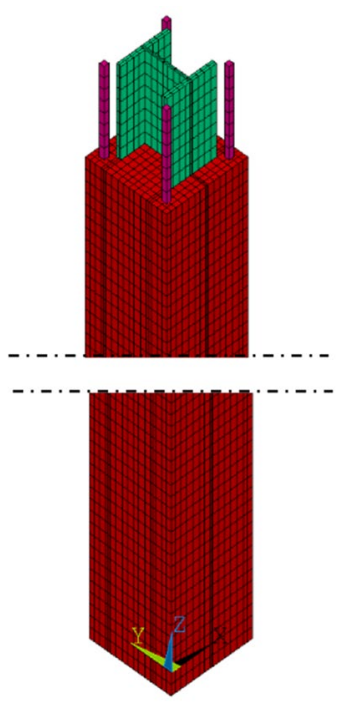

(b) TEC
Fig. 6 Finite element approximation for composite columns

and concrete, LINK33 is used to model the reinforcement. Figure 7 shows the shape of each finite element. The mesh size used for finite element approximation is $20 \mathrm{~mm}$ and $15 \mathrm{~mm}$, respectively, for concrete and steel profile in the cross section, with 80 element divisions in the longitudinal direction, as it is taken in several works (Albero et al. 2016; Espinos et al. 2012).

A perfect contact is assumed between the rebars and concrete. The integration time step is set to $60 \mathrm{~s}$, but it may decrease to $1 \mathrm{~s}$. The criterion for convergence uses a tolerance value of the heat flow, smaller than $0.1 \%$ with a minimum reference value of $1 \times 10^{-6}$. The temperature field was determined for the total time of $7200 \mathrm{~s}$ (120 min). Figure 8 shows a temperature distribution for the composite column after $120 \mathrm{~min}$ of fire.
The second step considers a static and Eigen buckling analysis. The static analysis assumes a small displacement theory with the prestress effects, being the Block Lanczos method used with the extraction of three buckling modes. The numerical solution assumes a perfect material and an ideal linear elastic behaviour, so the real loadbearing buckling resistance will be smaller than the calculated elastic buckling load. The buckling length and the first mode shape are illustrated in Fig. 9.

During this second step of simulation, new finite elements are applied, switching from thermal to mechanical model, notably SOLID185 and LINK180 (Albero et al. 2016). SOLID65 is added to the 3D model to represent the solid concrete without reinforcing bars. This element is capable of cracking in tension and crushing in compression even when using the non-linear analysis. Figure 10 shows the shape of each finite element.

For non-linear analysis (third step of simulation), the imperfection is included. This imperfection is based on the first Eigen buckling model duly scaled to the maximum considered imperfection. For most of the real-world structures, the maximum imperfection is taken equal to $L / 150$ ( $L$ height of column) as recommended by EN-19931-1 in section 5-3-2 for buckling curve $C$ (CEN 2005). The Arc-length solution method is used in this simulation with a minimum and maximum incremental load, being the convergence criterion based on displacement, with a convergence tolerance of $5 \%$.

In order to avoid convergence difficulties due to the localized effect of the loading and supports, a rigid plate was applied to both ends. Pin-ended boundary conditions are considered for the composite column in this study, i.e. only the mid line nodes of the rigid loading plate are restrained. Incremental uniform compressive load is applied on the top of the rigid plate, as shown in Fig. 11.

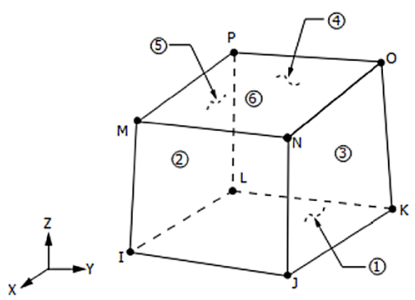

(a) SOLID70, thermal analysis of steel concrete.

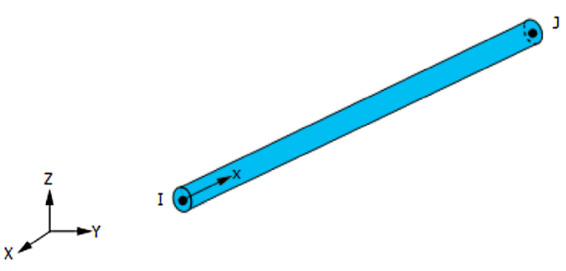
(b) LINK33, thermal analysis of
rebars.

Fig. 7 Thermal finite elements used to build the three dimensional model of composite columns (ANSYS INC 2016) 


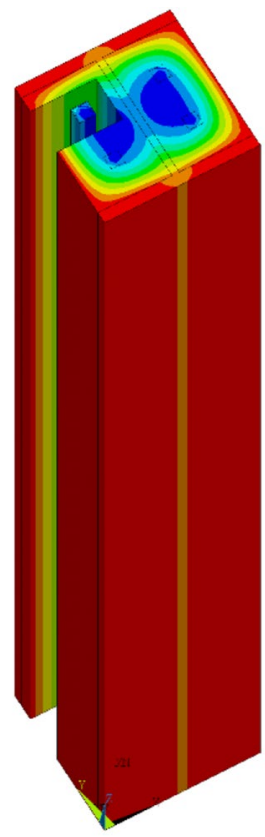

(a) PEC HEB220

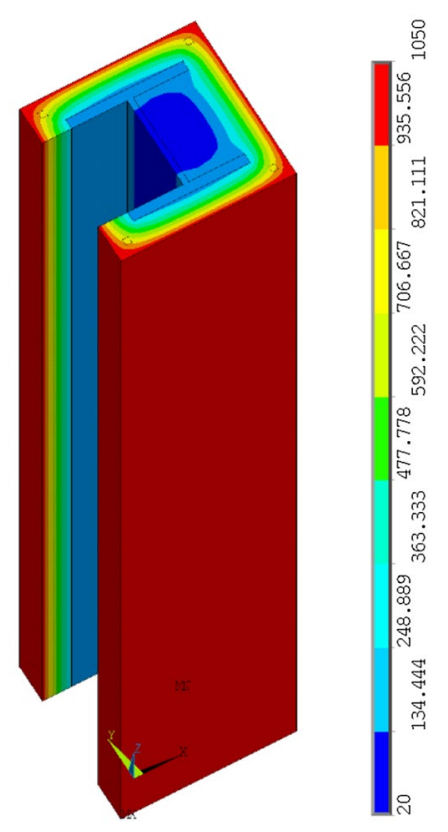

(b) TEC HEB160

Fig. 8 Temperature field for the composite columns, after $120 \mathrm{~min}$
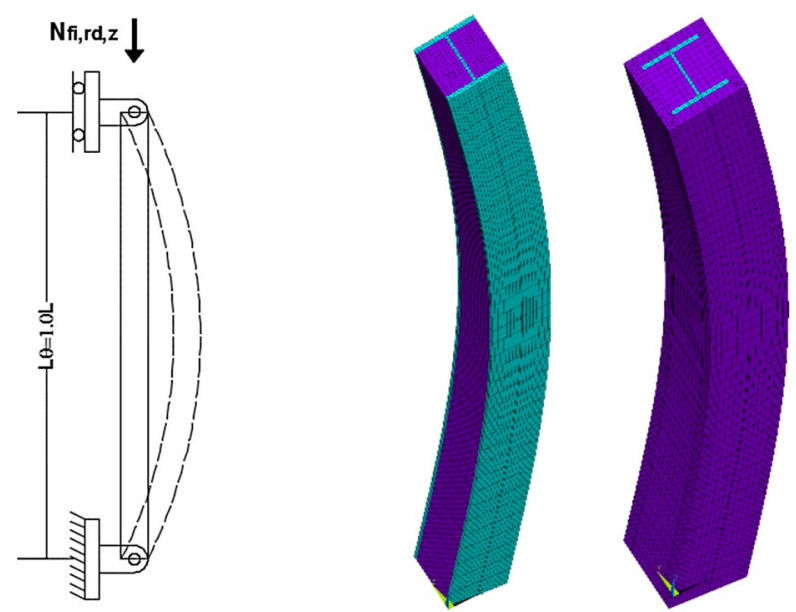

(a) buckling length in fire

(b) deformed shape mode

Fig. 9 Elastic buckling result

\section{Result and discussion}

\section{Temperature field}

Five different locations over the concrete were selected to represent the temperature evolution with the regard to standard fire ISO-834 (International Organization

for Standardization 1999), as illustrated in Fig. 12. As expected, the temperature decreases when approaching the centre of the cross section as result of concrete protection. The temperature field does not change along the length of the column. It is noted that the concrete column temperature varies from 20 to $1035^{\circ} \mathrm{C}$, while the fire source reaches around $1049{ }^{\circ} \mathrm{C}$ after $2 \mathrm{~h}$ of heating. By increasing the time of exposure, all the curves tend to converge to the same temperature, indicating the loss of fire resistance.

The temperature evolution of the columns with same cross-section geometries (PEC HEB220) but with different types of concrete (NSC, HSC) is illustrated in Fig. 13. Since the thermal conductivity of the steel profile is larger than that of the concrete, the maximum temperature in the flange is great than of that of the concrete, which affects the loadbearing capacity of the composite column. However, the temperature in the web is approximately the same as in the normal strength concrete, see Fig. 13a, due to the presence of concrete protection between the flanges. For highstrength concrete model, there is a slight difference between the temperature in web profile and the concrete as shown in Fig. $13 \mathrm{~b}$. The reduction of the heating rate observed on the flange and web of the steel profile, in the range temperature of $750{ }^{\circ} \mathrm{C}$ and $800{ }^{\circ} \mathrm{C}$, is due to the allotropic phase transformation from the ferrite phase to the austenitic phase (see Fig. 2d).

The temperature evolution of the TEC columns (TEC HEB160) with different types of concrete (NSC, HSC) is depicted in Fig. 14. The concrete presents the highest temperature when compared with steel profile related to his exposition to fire, however, the temperature in column with HSC presents higher temperature level. The maximum temperature in the centre of columns (web) reaches $503.67{ }^{\circ} \mathrm{C}$ for NSC protection and $555.32{ }^{\circ} \mathrm{C}$ for $\mathrm{HSC}$ protection after $120 \mathrm{~min}$ of fire exposure. This suggests that NSC protects steel profile better than HSC.

The effect of fire in PEC is plotted in Fig. 15, according to both concrete types. The difference between the maximum and minimum temperature depends on the concrete type. The results show that the use of HSC reduces the level of fire protection with the regard to NSC in approximately $74{ }^{\circ} \mathrm{C}$ of difference between minimum and maximum temperature, after $120 \mathrm{~min}$ of fire exposure. This behaviour is justified by the high thermal conductivity and low specific heat of HSC. The steel profiles heat faster when HSC is used.

The effect of fire in TEC is represented in Fig. 16. According to the thermal simulation, the temperature field increase with increase of time exposure. The results show that the HSC heat faster than NSC because of its high thermal conductivity. The difference between the minimum temperature on NSC and that of $\mathrm{HSC}$ is $52^{\circ} \mathrm{C}$ after $120 \mathrm{~min}$ of fire exposition. However, the cover thickness of concrete increases the fire protection of profile, therefore TEC 


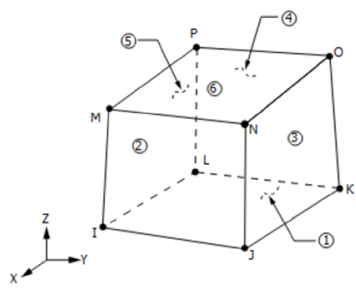

(a) SOLID185, mechanical analysis of steel.

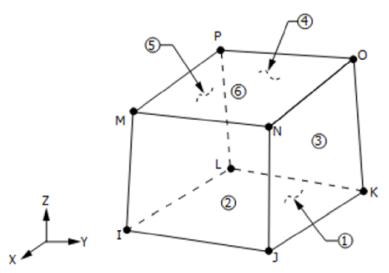

(b) SOLID65, mechanical analysis of concrete.
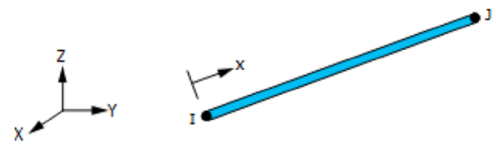
(c) LINK180, mechanical
analysis of rebars.

Fig. 10 Structural finite elements used to build the 3D model of composite columns (ANSYS INC 2016)

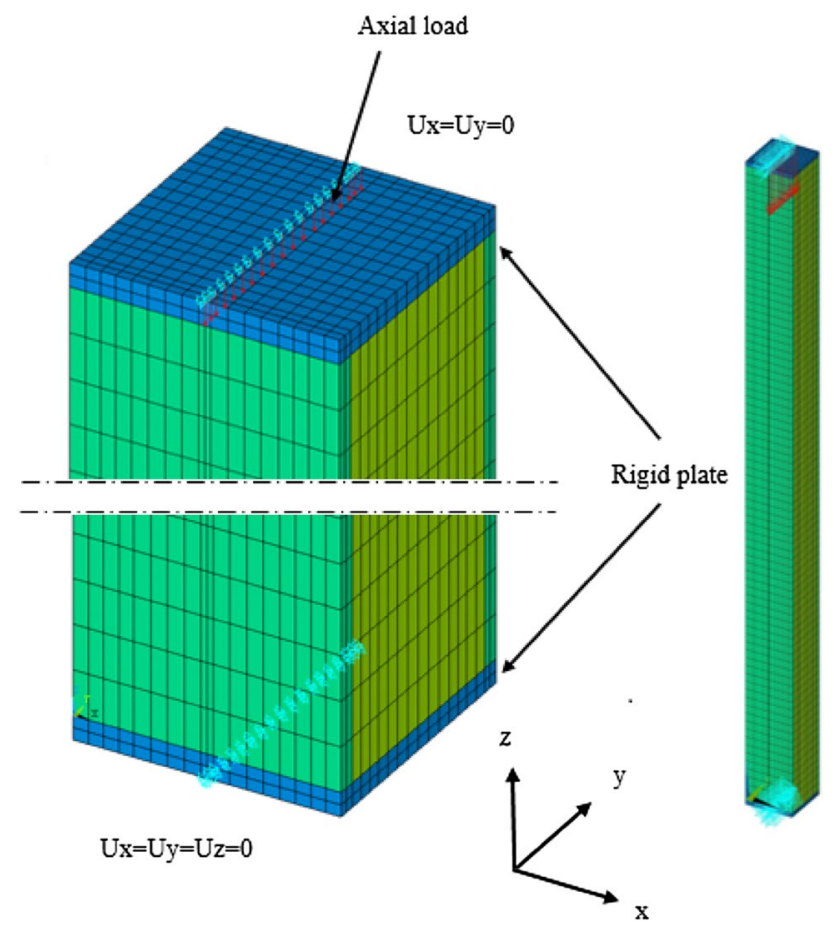

Fig. 11 Numerical model, discretization and boundary conditions

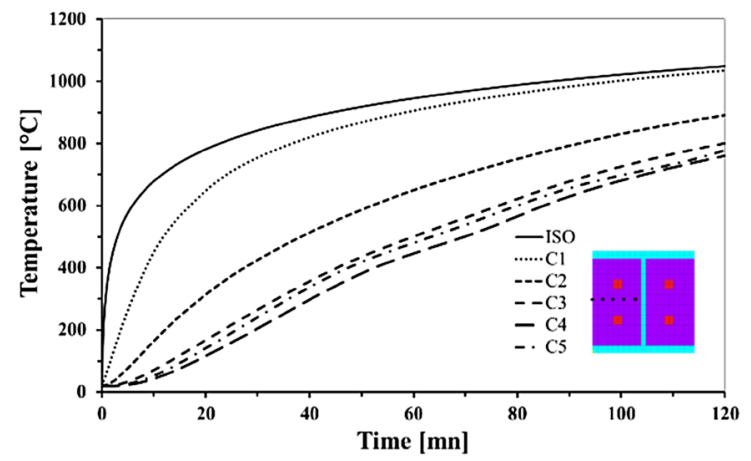

Fig. 12 Temperature evolution HSC PEC HEB220 presents higher fire protection than PEC, moreover, the concrete corner shows higher temperature caused by the heat transfer from two sides.

\section{Non-linear buckling load}

The buckling load of composite columns at elevated temperature is associated with the cross-section area, materials strength and time-temperature history. Figure 17 shows the variation of buckling resistance of composite columns as a function of fire exposure time. The buckling load decreases with increasing fire exposure time, independent of the material type. The reduction in buckling load is more pronounced for HSC than for NSC. This is probably due to the high thermal conductivity of HSC. A decrease of around $35 \%$ in loadbearing capacity between the two materials is found at ambient temperature indicating the best structural performance of HSC, however, after approximately 55 min under fire, the two materials got the same value of buckling load (see Fig. 17a). For TEC section, a difference of around 55\% in loadbearing capacity is observed between both materials at room temperature, maybe associated with highest relative percentage of concrete, and consequently related to the mechanical properties of each material (see Fig. 3).

The lateral displacement versus load is illustrated in Fig. 18. This graph shows that the lateral displacement at the mid-height of the column increases with increasing the axial load up to the maximum loadbearing capacity. The comparison in Fig. 18a indicates that at low fire exposure time, column made with HSC presents a high buckling load with regard to NSC. However, at elevated fire exposure time, the behaviour is reversed. It is thought that this is attributed to the difference in the thermal behaviour. For PEC column, the loadbearing capacity of HSC exceeds approximately that of NSC in $15 \%$ at R30. After 90 min of fire, this difference is reduced. Under fire and independently of the exposure time, the deflection in column made with HSC is smaller than that of NSC (around 25\%) because of the stress-train relationship 


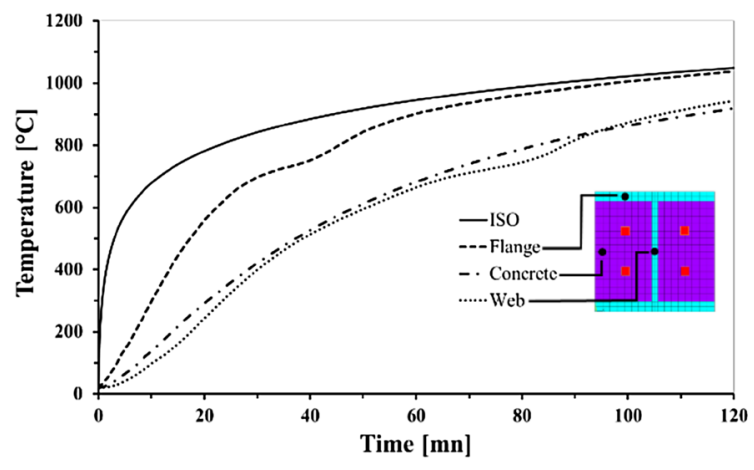

(a) NSC PEC HEB220.

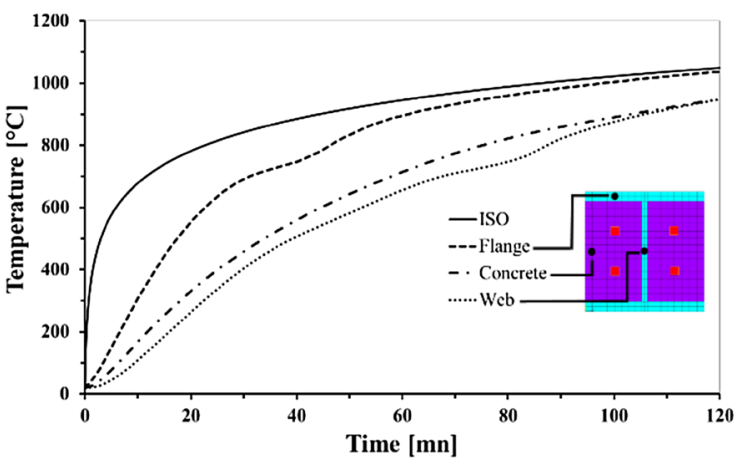

(b) HSC PEC HEB220.

Fig. 13 Comparison of temperature evolution

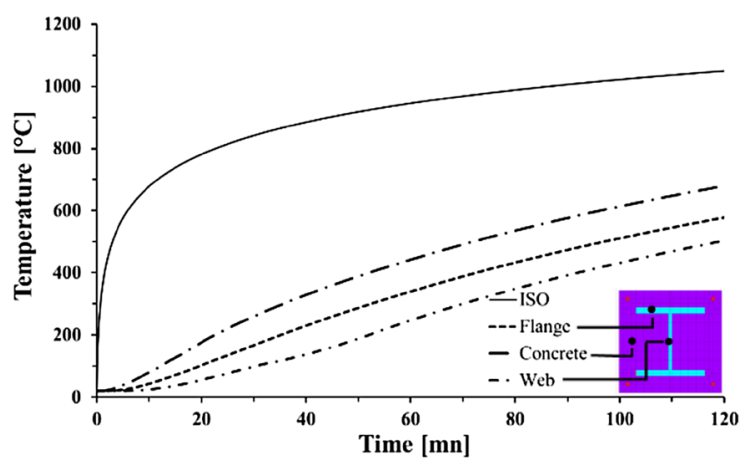

(a) NSC TEC HEB160.

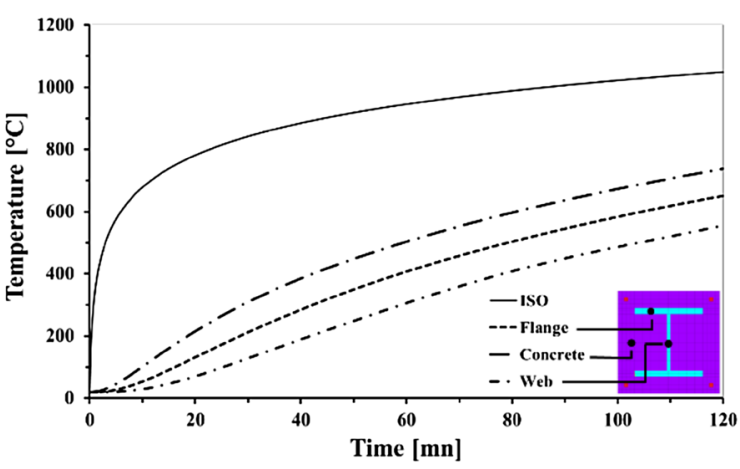

(b) HSC TEC HEB160.

Fig. 14 Comparison of temperature evolution
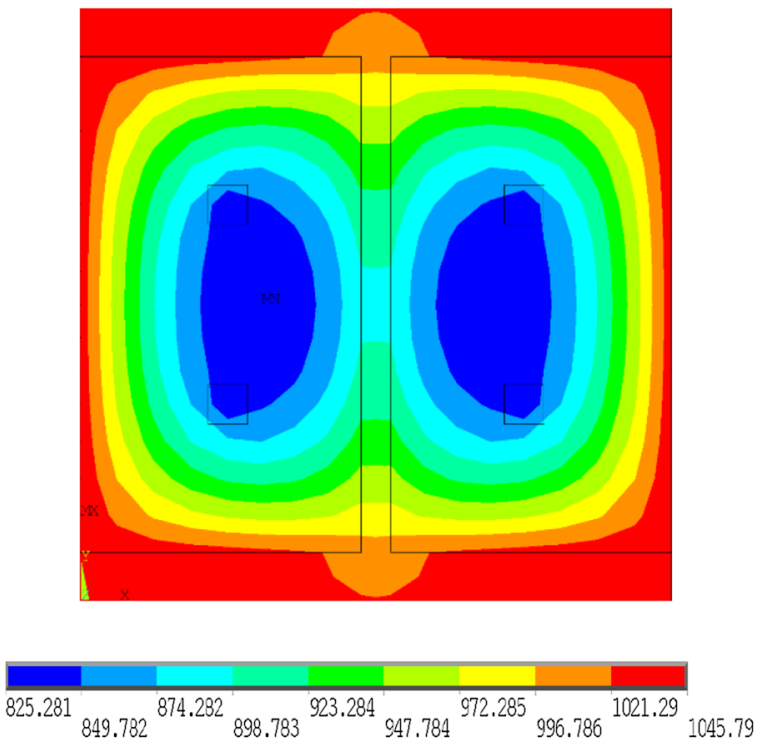

(a) NSC
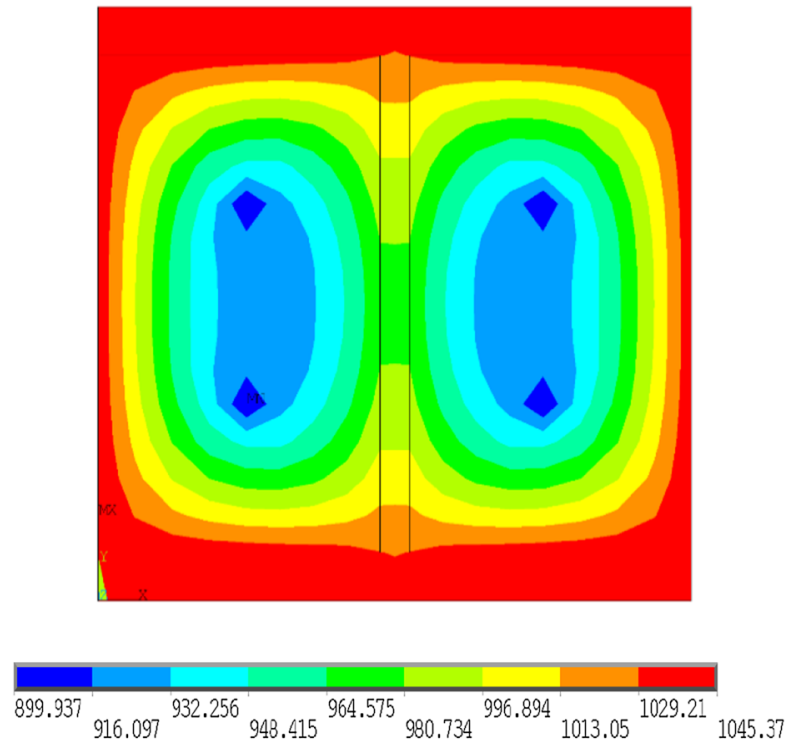

(b) HSC

Fig. 15 Temperature distributions (R120) PEC 


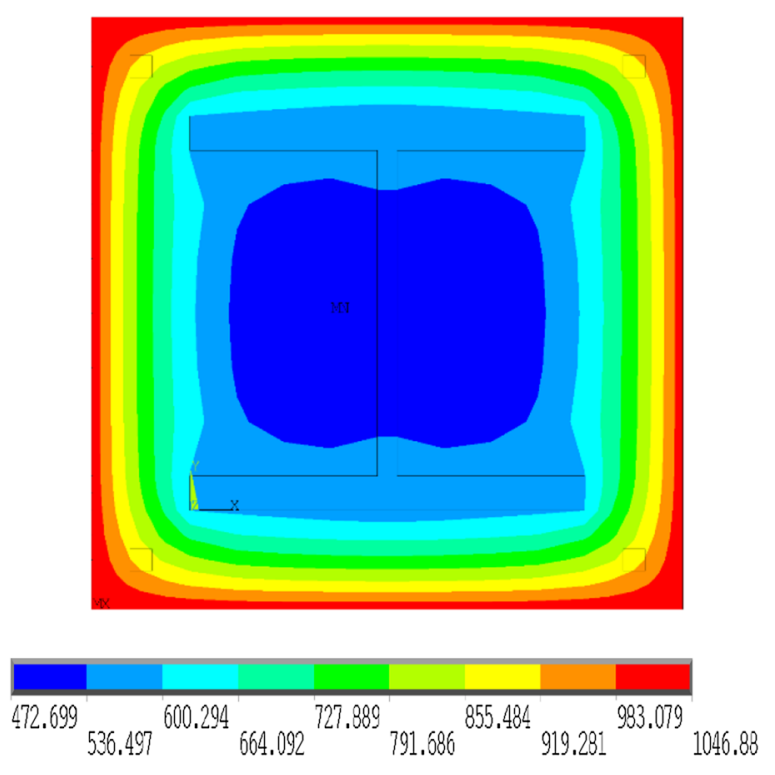

(a) NSC

Fig. 16 Temperature distributions (R120) TEC

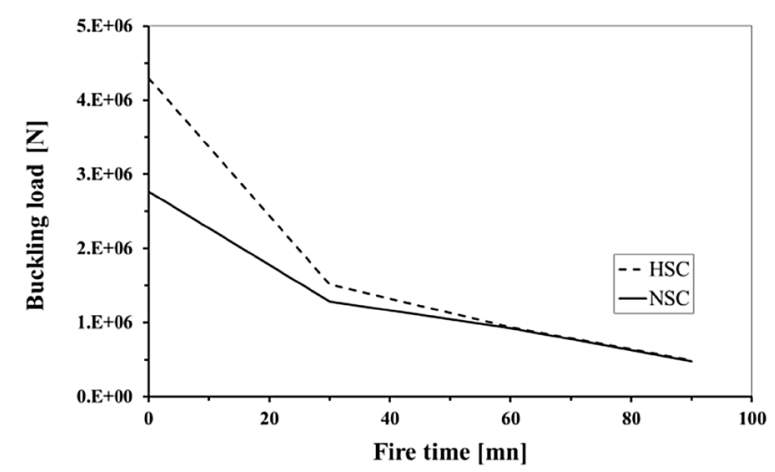

(a) PEC HEB220.

Fig. 17 Comparison result of buckling load

of each material (ductility). In Fig. 18b, it is shown the same behaviour of concrete as in PEC section, moreover, it can be seen that the use of NSC provides a larger deflection than HSC (about $60 \%$ of difference), which may be beneficial for evacuating the occupants in fire accident (safety case). For the continuous structure, the elements continue to support the external loads without collapse and this is due to the load redistribution within the structure (Hoang 2010). In such situation, the maximum loadbearing capacity of materials is not so important as the ductility. According to Fig. 18a, $\mathrm{b}$, it can be seen that the lateral displacement of the composite columns is relatively small, even the solution method accounts for large displacement theory. This is mainly due to the high stiffness of the composite column. Such behaviour

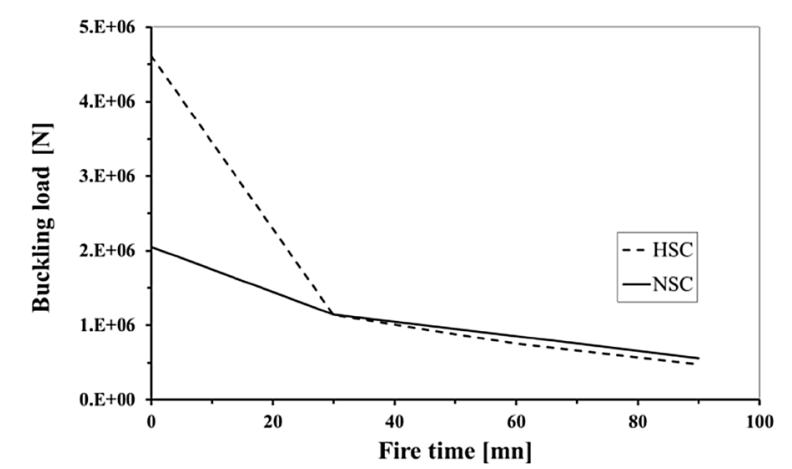

(b) TEC HEB160.
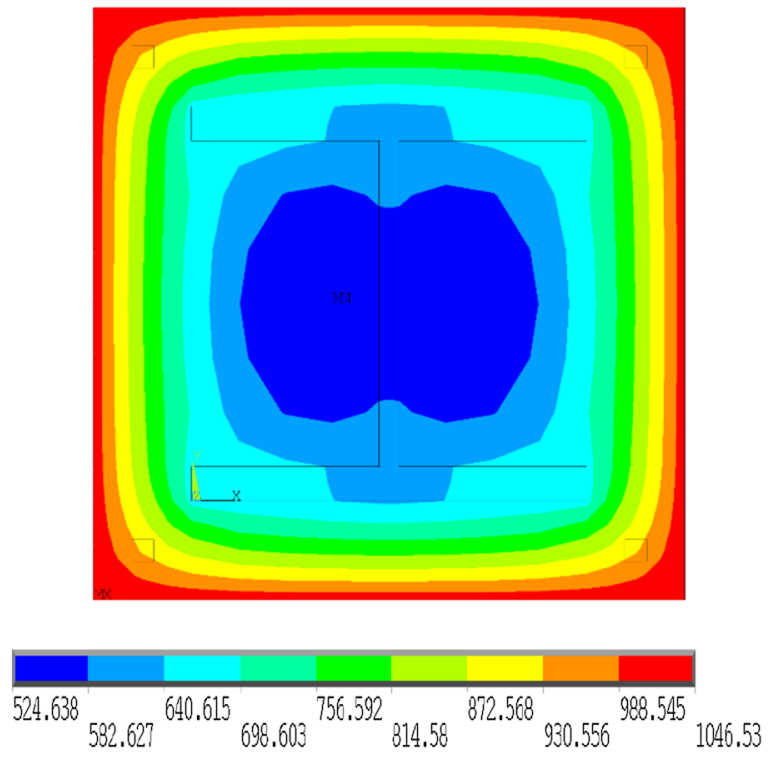

(b) HSC

for composite elements is found elsewhere in the literature (An and Han 2014; Chicoine et al. 2002). In this study, concrete material is assumed to have a non-linear behaviour without cracking or crashing, therefore the failure mode is due to the loss of stability of the composite column.

\section{Comparison of result using the advanced method and simplified method}

The buckling load results found with finite elements simulation are compared with those obtained by simple calculation method (CEN 2004, 2005), for room temperature conditions and fire. The current field of the calculation method 


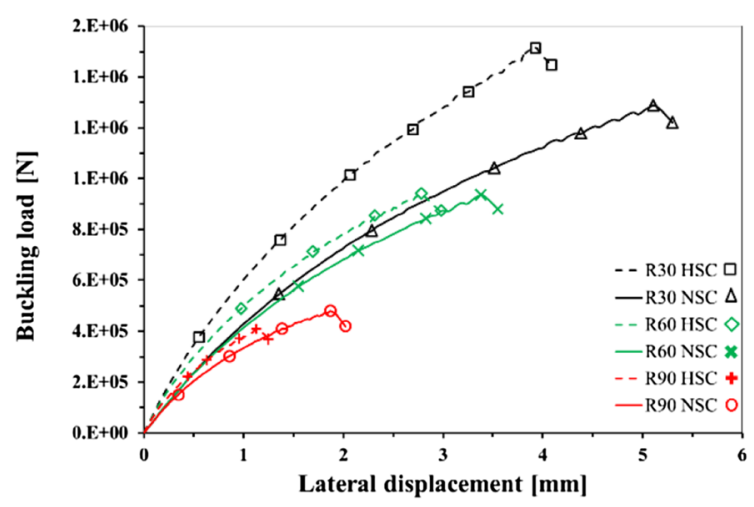

(a) PEC HEB220.

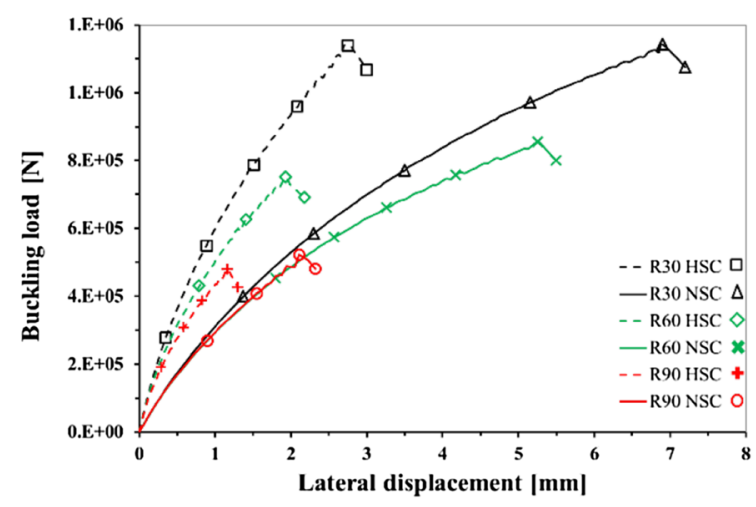

(b) TEC HEB160.

Fig. 18 Lateral displacement-load curve

is limited to concrete grade between $\mathrm{C} 20 / 25$ and C50/60. So, only the results for NSC will be compared in this section. The buckling resistance is calculated by the following expression:

$N_{\mathrm{fi}, \mathrm{Rd}, \mathrm{z}}=\chi \cdot N_{\mathrm{fi}, \mathrm{pl}, \mathrm{Rd}}$,

where $N_{\text {fi,pl,Rd }}$ is the plastic resistance of the composite section to axial compression, $\chi$ is a reduction coefficient, deduced from the non-dimensional slenderness ratio $\bar{\lambda}_{\theta}$ as represented in the following formula:

$\bar{\lambda}_{\theta}=\sqrt{N_{\mathrm{fi}, \mathrm{pl}, \mathrm{R}} / N_{\mathrm{fi}, \mathrm{cr}, z}}$

$N_{\text {fi,pl, R }}$ is the plastic resistance considering the safety factors equal to unity, $N_{\text {fi,cr, } z}$ represents the Euler buckling load in fire situation, given as follows:

$N_{\mathrm{fi}, \mathrm{cr}, z}=\pi^{2} \times(E I)_{\mathrm{fi}, \mathrm{eff}, z} / L_{\theta}^{2}$

where $L_{\theta}$ is the effective length of the column, $E I$ is the sum of the reduced elastic modulus $E$ and the second moment of area $I$ for the different components (CEN 2005).

The numerical and analytical results of the buckling load column are compared in Table 3. It can be seen that most of the simulation results are in agreement with that of the simplified method with a difference smaller than $5 \%$ except for TEC section at R60 and R90. It is to be noted that the average temperature in TEC section is deduced from the finite element method and used in the simplified method. The simplified method does not include formulas to calculate the average temperature in TEC composite column. The higher differences between the analytical and the numerical results for TEC section maybe attributed to the combination of both methods in the analysis of the behaviour of the composite column. However, the temperature evaluation of the PEC section is calculated according to Annex G (CEN 2005). The mechanical performances (load bearing capacity) of the
Table 3 Buckling load, comparison between the numerical and analytical results

\begin{tabular}{|c|c|c|c|}
\hline Fire rating class & $\begin{array}{l}\text { Numerical } \\
\text { results } N_{\text {fi,rd }}(\mathrm{N})\end{array}$ & $\begin{array}{l}\text { Analytical } \\
\text { results } \mathrm{N}_{\mathrm{fi}, \mathrm{rd}} \\
\text { (N) }\end{array}$ & Difference $(\%)$ \\
\hline \multicolumn{4}{|l|}{ PEC } \\
\hline$t=0$ & $2,763,900$ & $2,700,000$ & 02 \\
\hline $\mathrm{R} 30$ & $1,287,687$ & $1,307,070$ & 01 \\
\hline R60 & 925,564 & 889,214 & 04 \\
\hline R90 & 481,539 & 502,166 & 04 \\
\hline \multicolumn{4}{|l|}{ TEC } \\
\hline$t=0$ & $2,050,180$ & $2,176,987$ & 05 \\
\hline R30 & $1,142,300$ & $1,136,519$ & 01 \\
\hline R60 & 855,109 & $1,024,813$ & 16 \\
\hline R90 & 560,810 & 833,524 & 32 \\
\hline
\end{tabular}

columns at room temperature are reduced more than twice after $30 \mathrm{~min}$ of fire exposure. This confirms the importance to consider the fire conditions in the design of composites structures.

\section{Conclusions}

The effect of the type of concrete in composite columns was investigated to calculate the non-linear buckling resistance in fire situations and the following conclusions can be made:

- Due to the limitations of the analytical method, the use of a numerical model (ANSYS) has allowed to describe the non-linear behaviour of composite columns made with normal and high strength concrete under fire.

- NSC concrete presents higher fire resistance than HSC concrete at elevated temperature. 
- At higher fire rating classes, smaller buckling loads in composite columns are found as expected.

- The buckling load results indicate that the use of HSC concrete in composite columns shows a higher degradation at elevated exposure time compared with NSC concrete, particularly when using totally encased column (TEC).

- The use of HSC concrete is beneficial for composite columns regarding its best performance at low fire exposure time. However, this behaviour is not observed at higher exposure time.

- NSC in composite structures provides more deflections than HSC (about $60 \%$ of difference), which may be useful during fire accident (safety level).

- The mechanical performance (loadbearing capacity) in composite columns at ambient temperature are reduced more than twice after $30 \mathrm{~min}$ of fire exposure. This confirms the importance to consider the fire conditions in the design of composites structures.

- Generally, the results determined by advanced calculation method are in agreement with simplified method, with exception to the higher fire ratings of TEC.

\section{Compliance with ethical standards}

Conflict of interest On behalf of all authors, the corresponding author (Abdelkadir Fellouh) states that there is no conflict of interest.

\section{References}

Afroughsabet, V., \& Ozbakkaloglu, T. (2015). Mechanical and durability properties of high-strength concrete containing steel and polypropylene fibers. Construction and Building Materials, 94, 73-82.

Albero, V., Espinos, A., Romero, M. L., Hospitaler, A., Bihina, G., \& Renaud, C. (2016). Proposal of a new method in EN1994-1-2 for the fire design of concrete-filled steel tubular columns. Engineering Structures, 128, 237-255.

An, Y.-F., \& Han, L.-H. (2014). Behaviour of concrete-encased CFST columns under combined compression and bending. Journal of Constructional Steel Research, 101, 314-330.

ANSYS INC. (2016). ANSYS ${ }^{\circledR}$ Academic Research, Release 16.2, Help System, Element reference. Canonsburg: ANSYS, Inc.

Bamonte, P. (2008). On the role of second-order effects in HSC columns exposed to fire. In Proceedings of 5th international conference structures in fire-SiF'08 (pp. 440-450).

CEN. (2004a). European Committee for Standardization, EN 1992-1-2: Design of concrete structures-part 1-2: General rules-Structural fire design, vol. EN 1992. Brussels: CEN-European Committee for Standardization.

CEN. (2004b). European Committee for Standardization, Eurocode 4: Design of composite steel and concrete structures-part 1-1: General rules and rules for buildings. Brussels: CEN-European Committee for Standardization.

CEN. (2005a). European Committee for Standardization, EN 1994-12: Design of composite steel and concrete structures. Part 1-2:
General rules-structural fire design. Brussels: CEN-European Committee for Standardization.

CEN. (2005b). European Committee for Standardization, EN 1993-1-2: European Standard Eurocode 3: Design of steel structures-part 1-2: General rules—structural fire design, CEN-Europ. Brussels: CEN-European Committee for Standardization.

CEN. (2005c). European Committee for Standardization, Eurocode 3: Design of steel structures-part 1-1: General rules and rules for buildings. Brussels: CEN-European Committee for Standardization.

Chicoine, T., et al. (2002). Behavior and strength of partially encased composite columns with built-up shapes. Journal of Structural engineering, 128(3), 279-288.

Espinos, A., Romero, M. L., \& Hospitaler, A. (2012). Simple calculation model for evaluating the fire resistance of unreinforced concrete filled tubular columns. Engineering Structures, 42, 231-244.

Fellouh, A., Benlakehal, N., Piloto, P., Ramos, A., \& Mesquita, L. (2016). Load carrying capacity of partially encased columns for different fire ratings. Fire Research, 1(23), 13-19.

Gernay, T. (2016). Fire performance of columns made of normal and high strength concrete: A comparative analysis. Key Engineering Materials, 711, 564-571.

Hoang, H. (2010). Structural continuity effects in steel frames under fire conditions. Masters Theses (All Theses, All Years), 420, Worcester Polytechnic Institute.

International Organization for Standardization. (1999). ISO834-1: Fire-resistance tests-elements of building construction-part 1: General requirements. Geneva: International Organization for Standardization.

Kodur, V. (2014). Properties of concrete at elevated temperatures. ISRN Civil Engineering, 2014, 468510.

Kodur, V. K. R., \& Khaliq, W. (2011). Effect of temperature on thermal properties of different types of high-strength concrete. Journal of Materials in Civil Engineering, 23(6), 793-801.

Kodur, Venkatesh, \& Mcgrath, Richard. (2003). Fire endurance of high strength concrete columns. Fire Technology, 39(1), 73-87.

Kodur, V. K. R., \& Sultan, M. A. (2003). Effect of temperature on thermal properties of graphene. Journal of Materials in Civil Engineering, 15(2), 101-107.

Kodur, V. K. R., Wang, T. C., \& Cheng, F. P. (2004). Predicting the fire resistance behaviour of high strength concrete columns. Cement and Concrete Composite, 26(2), 141-153.

Luccioni, B. M., Figueroa, M. I., \& Danesi, R. F. (2003). Thermomechanic model for concrete exposed to elevated temperatures. Engineering Structures, 25(6), 729-742.

Moliner, V., Espinos, A., Romero, M. L., \& Hospitaler, A. (2013). Fire behavior of eccentrically loaded slender high strength concretefilled tubular columns. Journal of Constructional Steel Research, 83(12), 137-146.

Piquer, A., \& Hernández-Figueirido, D. (2016). Protected steel columns vs partially encased columns: Fire resistance and economic considerations. Journal of Constructional Steel Research, 124, 47-56.

Rodrigues, J. P. C., Correia, A. J. M., \& Pires, T. A. C. (2015). On the role of second-order effects in HSC columns exposed to fire. Journal of Constructional Steel Research, 105, 97-106.

Schaumann, P., Kodur, V., \& Bahr, O. (2009). Fire behaviour of hollow structural section steel columns filled with high strength concrete. Journal of Constructional Steel Research, 65(8-9), 1794-1802.

Publisher's Note Springer Nature remains neutral with regard to jurisdictional claims in published maps and institutional affiliations. 